\title{
EL GRYLOS: PRIMER ESCRITO DE ARISTÓTELES
}

Alberto Buela*

RESUMEN - Se presentan al castellano, entendemos que por primera vez, los fragmentos que componen los testimonios acerca del Grylos. Se sostiene que no fue un epitafio de Aristóteles a Grylos, como habitualmente se sostuvo, sino una polémica de aquél con los retóricos sofistas a propósito de los encomiásticos epitafios que éstos escribieron con motivo de la muerte de Grylos. Asímismo se afirma que no fueron ejercicios de ingenio (excercere ingenia) debidos a la sutileza (subtilitatis suae) de Aristóteles como afirma Quintiliano sino una respuesta indirecta de Platón a Isócrates a través de su discipulo.
ABSTRACT - It's the first time, we think, that the fragments composing the witnesses on the Grylos are exhibited to the Spanish world. The article asserts that this work was not an epitaph written by Aristotle for Grylos, as many state, but a polemic with the sophists about their encomiastic writings when Grylos was dead. Here is also affirmed that the Grylos must not be considered as exercises of Aristotle's skill and subtility, according to Quintilian, but as an indirect answer of Plato to Isocrates by means of the Lyceum's founder.

Es sabido que los textos de los autores griegos en su conjunto y los de Aristóteles en particular llegaron a nosotros después de un sin número de vicisitudes: pérdidas, recuperaciones, agregados y mutilaciones. El seguimiento de un escrito aristotélico es una historia apasionante para aquellos que alguna vez lo hemos intentado, pero... sembrada por un mar de dudas. Ni que decir, entonces, de este tipo de texto que intentamos interpretar aqui. De los escritos del Estagirita no poseemos nada que se asemeje a lo que hoy es un libro. Incluso no poseemos stricto sensu ningún manuscrito suyo. Poseemos sí, códices, y manuscritos de segundas o terceras manos.

La historia un tanto novelada de los vaivenes de estos escritos hasta Andrónico de Rodas (siglo I a.C.), quien organiza por primera vez seriamente los mismos es, según los testimonios de Estrabón y Plutarco, la siguiente: Aristóteles lega su biblioteca a su discípulo Teofrasto. Este, a su vez, a Neleo, quien la llevó a su patria - Skepsis de Ida, Asia Menor - pero por temor a se apoderasen de ella los enviados del rey de Pérgamo la ocultó en una gruta, donde quedó hasta el año 100

Diretor da revista Disenso, Buenos Aires.

\begin{tabular}{|l|l|l|l|l|l}
\hline VERITAS & Porto Alegre & v. 42 & $\mathrm{n}^{\circ} 1$ & Março 1997 & p. 91-95
\end{tabular}


a.C. Fue adquirida por un coleccionista, Apelicón de Teos. Este la transladó a Atenas, donde se apoderó de ella Sila en el año 86 llevándola a Roma como botín de guerra. Su hijo Fausto la vendió en el 55 para pagar las deudas de su padre. El gramático grego Tiranión de Amisos se encargó de restaurar los manuscritos y realizó una primera copia parcial. Y luego una segunda en donde aparece ya Andrónico de Rodas - décimo escolarca del Liceo - ordenando la obra por materias.

En cuanto a los escritos de juventud sólo tenemos fragmentos aislados y menciones indirectas. Los textos más importantes, sea por su extensión, sea por su significación, son: Sobre el bien con seis fragmentos; Sobre las Ideas con cinco; El Eudemo con doce; Sobre la filosofia con veintiocho y El Protréptico con ciento diez fragmentos en la versión de I. Düring. ${ }^{3}$

En cuanto al texto que nos ocupa sólo existen dos fragmentos de referencia y ello como menciones indirectas. Esto es, no vamos a leer a Aristóteles sino lo que Diógenes de Laercio y Quintiliano dicen que dijo El Filósofo.

El primer fragmento corresponde, como acabamos de decir, a Diógenes de Laercio II, 55; equivalente al fragmento 68, página 75 en V. Rose: Aristotelis Fragmenta, Ed. Teubner, Stuttgart, 1966 (1ra. edición 1886) y al fragmento 1 en D. Ross: Aristotelis Fragmenta Selecta, Oxonii, 1955.

El segundo fragmento corresponde a Quintiliano, quien hace mención al Grylos en sus Institutio Oratoria, II, 17-14; equivalente al fragmento 69 en V. Rose: op. cit. y al fragmento 2 en D. Ross: op. cit.

Para comenzar es interesante notar que Grylos aparece en el catálogo de las obras de Aristóteles conservado por Diógenes de Laercio bajo el nombre Perì rhe-

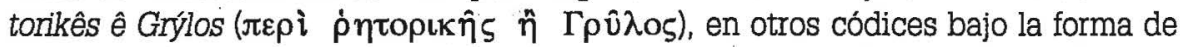

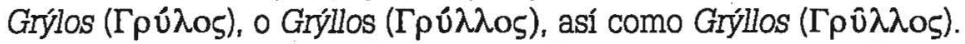

El título de la obra El Grylos o Sobre la retórica ya nos está dando una pista acerca de la temática de la misma. Se trata, pues, de un trabajo acerca de la retórica.

A su vez, el fragmento primero perteneciente, como se dijo, a Diógenes de

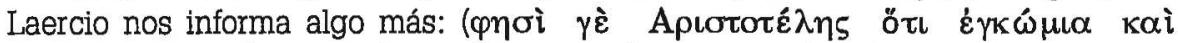

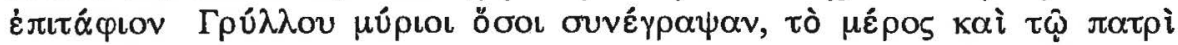
$\chi \alpha p ı \zeta o ́ \mu \varepsilon v o \imath)$ "Aristóteles dice que muchos escribieron sobre Grylos discursos encomiásticos y epitafios, en parte, con la intención de congraciarse con su padre".

Este pequeño fragmento nos ofrece sabrosos datos para la interpretación del Grylos. Primero su fecha aproximada de redacción. La obra, obviamente, fue redactada después de la muerte de Grylos, hijo de Jenofonte, personaje espartano refugiado en. Atenas quien con la alianza provisoria entre las dos ciudades griegas antes de la batalla de Mantinea aparecía como un futuro importante hombre público de Esparta. Esta última posibilidad explica las adulaciones chanizómenói

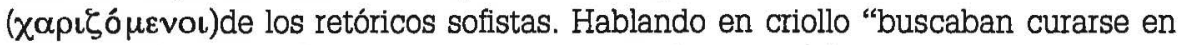
salud" por lo que pudiera pasar con un personaje potencialmente importante como Jenofonte. La ocasión fue propicia pues su amado hijo Grylos murió en el combate

1 DÜRING, Ingemar. Aristote's Protrepticus, an Attempt of Reconstruction. Stockholm, 1961. 
de Mantinea en el año 362 a.C. Esta fecha nos da idea aproximada de la redacción del trabajo, la que no puede ir más allá del 361 a.C.

Nuestro filósofo tiene en la fecha veintitres jóvenes años y su maestro sesenta y seis. Platón está en su etapa de madurez o plenitud, momento en el que logra desarrollar su teoría propia con espléndido dominio de la expresión literaria. Y Aristóteles, mientras tanto, absorbe cual una esponja. En la época la propuesta de Platón de un humanismo científico-filosófico estaba contradicha por la propuesta del famoso Isócrates que propugnaba un humanismo retórico-literário.

En segundo lugar podemos observar que el término charizesthai

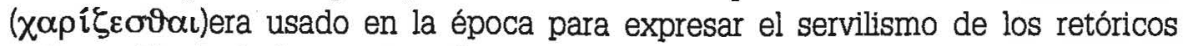
sofistas. Platón lo hace reiteradamente en el Gorgias 462c; 501b; 502e; 513d; y 521b, casualmente, el diálogo donde se ocupa de la definición de la retórica. La idea de "causar agrado", de "complacer" propia de los retóricos sofistas se contrapone a la del orador de Platón que "habla para el mayor bien de los que le escuchan, tendiendo a que los ciudadanos se hagan mejores por sus discursos" (Gorgias, 502,e).

Podemos, entonces, colegir que el Grylos no fue escrito para honrar la memoria del hijo de Jenofonte, como se ha sostenido tradicionalmente, sino que fue una reacción polémica ante los reiterados elogios fúnebres escritos por varios retóricos en ocasión de su muerte. De entre los retóricos se destaca Isócrates, el gran contradictor contemporáneo de Platón, de quién Diógenes nos informa que escribió un discurso encomiástico sobre Grylos. Isokrátên phêsì Grýllou enkômion

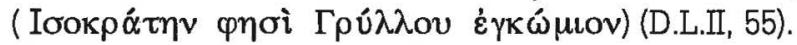

Estos múltiples elogios fúnebres para "causar agrado" daban la impresión que la retórica estuviera dirigida a obrar sobre los afectos y sentimientos. En una palabra, sobre la parte irracional del alma. Ello explica, en parte, la reacción del jóven Aristóteles acostumbrado a recibir en la Academia, ya lleva seis largos años en ella, la enseñanza de la primacía de lo racional por sobre lo irracional.

En tercer lugar podemos deducir, todos los estudiosos están de acuerdo, que dada la analogía cierta con el diálogo Gorgias y el método dialogal llevado por Platón a su máxima eficacia expresiva en sus enseñanzas, El Grylos fue escrito en forma de diálogo. Claro está que existe una objeción ilevantable, aquella que hace casi cuarenta años pusiera Pierre Thillet, nuestro jury en la Sorbona, cuando con agudeza observó "para que sea un diálogo se necesita la presencia de Grylos discutiendo de retórica. Y eso no lo tenemos, se trata de una mera conjetura."”

El fragmento segundo y último nos introduce de lleno en la argumentación que Aristóteles habría realizado en El Grylos. Se lo debemos, como dijimos, al retórico hispano Quintiliano, quien vivió durante el siglo I de nuestra era. Y fue descubierto a fines de la centuria pasada, más precisamente en 1886, por ese tenaz hurgador de bibliotecas que fue Don Valentín Rose.

El fragmento, bastante deshilvanado por cierto, dice asi: "transeamus igitur ad eam questionem quae sequitur, an rhetorice ars sit, quod quidem... ex iis qui

2 THILLET, Pierre. "Note sur Le Gryllos, ouvrage de jeunesse d'Aristote", Revue Philosophique de la France et de l'étranger, n. 82, 1957, p. 352-354. 
praecepta dicendi tradiderunt nemo dubitavit... sed cum his philosophi et Stoici et Peripatetici plerique consentiunt... equidem illos qui contra disputarunt non tam sensisse quod dicerent quam exercere ingenia materiae difficultate credo voluisse...quidam naturalem esse rhetoricem volunt...nihil quod ex arte fiat ante artem fuisse... non esse artis id quod faciat qui non didicerit, dicere autem homines et qui non didicerint. Aristoteles, ut solet, quaerendi gratia quaedam subtilitatis sua argumenta excogitavit in Grylo. Sed idem et arte rhetorica tres libros scripsit et in eorum primo non artem solum eam fatetur, sed ei particulam civilitatis sicut dialectices assignavit".

Quintiliano se dice: "Vayamos pues a la cuestión que sigue, si la retórica es arte, a propósito de lo cual recuerda que nadie duda, sobretodo aquellos que elaboraron las reglas del decir (los retóricos), también algunos filósofos como la mayor parte de los estoicos y de: los peripatéticos son de la misma opinión. Y aquellos que fueron de la opinión contraria, lo fueron no tanto porque lo sintieran sino mas bien, creo yo, por haber querido ejercitar el ingenio en las dificultades de la materia. (Algunos de sus argumentos son): la retórica es un don natural... nada de lo que por arte se haga puede ser anterior al arte... aquello que los hombres hacen sin haberlo primero aprendido no es arte. Aristóteles, como solía hacerlo, por el gusto de indagar, excogitó en El Grylos algunos de estos argumentos con su típica sutilidad. El mismo escribió después tres libros sobre el arte retórica, en el primero de los cuales sostiene que no es solamente un arte sino que le asignó una particular participación tanto en la política como en la dialéctica".

Por el segundo fragmento nos introducimos en la argumentación del Grylos. La cuestión es responder a la pregunta si la retórica es un arte? (an rhetorice ars sit). A lo que responde que ni los retóricos, ni los estoicos, ni los peripatéticos dudaron nunca en responder de modo afirmativo. Y que si algunos fueron de la opinión contraria lo hicieron, creo yo dice taxativamente Quintiliano, (credo voluisse) por haber querido ejercitar el ingenio en las dificultades de la retórica. Y a Ienglón seguido nos informa que Aristóteles por el gusto de indagar (quaerendi gratia) presentó a través de su discurso en el Grylos los siguientes argumentos: la retórica no puede ser arte, téchnê ( $\tau \varepsilon \dot{\chi} \chi \eta)$ porque en algunos hombres es un don natural, y lo que venga del arte no puede ser anterior al arte mismo. Y como "el arte es un hábito productor conforme a razón", al catalogar a la retórica como "don natural" y por ende allende la razón, le niega ab ovo su caracter de arte.

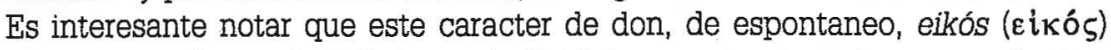
va a ser conservado por Aristóteles en la Retórica cuando al comienzo nomás dice "entre el vulgo algunos hacen esto (pratican la retórica) espontaneamente; otros, por la costumbre que procede de un hábito héxis" (ع̌ $\xi(\zeta)$ (1354a). No existe contradicción entre el Grylos y la Retórica, como algunos pretenden, sino mas bien que aquél se encuentra incorporado a ésta. Existe, eso sí, la distancia que media entre un escrito juvenil lleno de intuiciones no desarrolladas aún, y la plenitud acabada de un pensamiento filosófico de primera magnitud.

Excogitar: hallar algo a través del discurso y la meditación. 
Este fragmento de Quintiliano nos muestra, obviamente, que éste leyó El arte de la retórica del Filósofo, pero que juzgó el Grylos a partir de aquella obra y no por si. Valoró al El Grylos como un ejercicio escolar, incluso de cierta sutileza (quaedam subtilitatis sua), pero un ejercicio al fin. Y se le escapó lo fundamental: el Grylos va dirigido contra Isócrates, el único enemigo intelectual con funcionalidad política que en Atenas tenía su maestro Platón. No es para menos, había dos propuestas de humanismo diferentes y enfrentadas. Humanismos que no se limitaban al campus universitario como las propuestas actuales de los comunitaristas norteamericanos, sino que tenían y buscaban su proyección política práctica en el manejo de la ciudad.

Podemos deducir, entonces, que Aristóteles sale a enfrentar a Isócrates por sugerencia de su maestro. Es normal que esto haya sido asi, porque sucedió y sucede actualmente. El maestro expone y el discipulo rompe lanzas con los contradictores. 